\title{
Quality of Life Among Patients With Chronic Kidney Disease Who are Undergoing Haemodialysis at Two Selected Teaching Hospitals in Sri Lanka
}

\author{
M. A. S. S. Premadasa ${ }^{*}$, H. G. I. M. Hulangamuwa ${ }^{2}$, \\ W. A. D. H. Wijesooriya ${ }^{1}$ and T. D. Amarasekara ${ }^{3}$ \\ ${ }^{1}$ National Hospital of Sri Lanka, ${ }^{2}$ Teaching Hospital Anuradhapura, Sri \\ Lanka
}

${ }^{3}$ Department of Nursing and Midwifery, University of Sri Jayawardanapura, Sri Lanka

\section{Abstract}

Chronic Kidney Disease (CKD) has shown a rising trend in Sri Lanka. Haemodialysis (HD) is a method of managing patients with CKD. Improving and maintaining Quality of Life (QOL) is an essential goal of nursing care for patients with CKD. However, there is a paucity of data on QOL among patients with CKD who are undergoing HD in Sri Lanka. Therefore, this study aimed at assessing the QOL among patients with CKD who are undergoing $\mathrm{HD}$ at haemodialysis units in selected teaching hospitals in Sri Lanka. A descriptive cross-sectional study was conducted with purposively selected participants $(n=250)$ at haemodialysis units in the above settings. Data was obtained through two pre-tested questionnaires, Socio-demographic questionnaire and WHOQOL$\mathrm{BREF}$, and they were analysed using descriptive statistics. Ethical approval was obtained from the ethics review committee, KAATSU International University (KIU), Sri Lanka. Findings revealed that the majority of participants were male $184(73.6 \%)$, and belonged to the $30-64$ age group. Nearly half of them $(48.4 \%)$ have undergone

* Corresponding should be addressed to Ms. M. A. S. S. Premadasa, National Hospital of Sri Lanka², Teaching Hospital Anuradhapura, Sri Lanka

Email: spremadasa9@gmail.com

https://orcid.org/0000-0002-7636-8034

(Received 15th October 2018; Revised 25th August 2019; Accepted 10th September 2019) (C) OUSL)

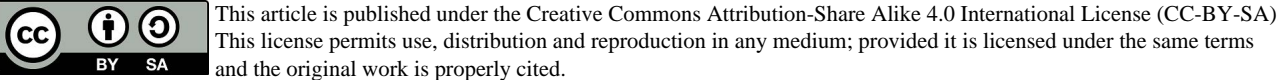


HD treatment for periods ranging from 3 months to 1 year duration, and $54 \%$ of them have been admitted three times per week for HD. Data revealed that the Environmental domain has the highest mean value (59.2 \pm 16.6$)$, and social relationship domain has the least (49.5 \pm 22.5$)$. Physical health and psychological domains were 51.9 (15.6), and 52.3 (19.9) mean values, respectively. Most of the participants (69.2\%) were observed having poor overall QOL. Statistically, significant $p$ values were as follows: Participants' education level $(\mathrm{p}=0.000)$, average monthly income $(\mathrm{p}=0.002)$ and the frequency of dialysis towards QOL $(\mathrm{p}=0.000)$. Health education programs should be organised to enhance QOL among patients with CKD and undergoing HD.

Key words: chronic kidney diseases, haemodialysis, quantitative research, Sri Lanka

\section{Introduction}

\section{Background of the study}

Chronic Kidney Disease (CKD) is a worldwide public health problem which leads to social, physical, economic and psychological issues. CKD prevalence is estimated to be $8-16 \%$ worldwide (Jha et al., 2013). In 2015, there were approximately 58 million deaths, with 35 million attributed to CKD globally (Levay et al., 2007).

According to the 2010 Global Burden of Diseases study (Mills et al.), CKD was ranked $27^{\text {th }}$ in the list of cause of a total number of deaths worldwide in 1999 , but raised to $18^{\text {th }}$ in 2010 (Jha et al., 2013). During 2011-2014 prevalence of CKD (stage 1-5) in the United States (USA) was $14.8 \%$ of adults, and the number has exceeded the prevalence of diabetic Mellitus (12.3\% - National Health and Nutrition Examination Survey-NHANES, 2011-2014). Annually, more than 500,000 individuals develop the end-stage renal disease (or CKD stage 5) in Sub-Saharan Africa, and the vast majority of these patients suffer premature mortality (Ojo, 2014).

According to the World Health Organization's (WHO) health profile in Sri Lanka, kidney disease is the seven the leading cause of death, with figures of $2.5 \%$ (WHO, Non-communicable country profile, 2014). Currently, in Sri Lanka, CKD prevalence can be seen in the North-Western, Eastern, Sothern and Central provinces and parts of the Northern provinces. However, previously, it was limited to the 
North-central and Uva provinces (Sunil, 2014).

End-Stage Renal Disease (ESRD) is the last stage of CKD, which requires renal replacement therapy (RRT) (Long, Wilkinson, Baldwin, and Wallin., 2014). The ability of the kidney to filter and remove waste and extra fluid from the body gets decreased due to CKD and acute kidney injury. Therefore, RRT is needed to manage the lives of patients with CKD. There are two types of renal replacement therapies: haemodialysis and kidney transplantation. Haemodialysis (HD) is a treatment option available for patients experiencing renal insufficiency, in which a machine is used to act out the function of the kidney such as filtering the blood and excretion of by-products (Ivey and Lane., 2010). HD is one of the most common procedures performed in US hospitals, and it was listed as five of the most common procedures for patient aged 45 - 65 years. It was identified that more than 6000 (approximately) people underwent HD in 2005. (Ranasinghe, Perera, Makarim, Wijesinghe and Wanigasuriya., 2011).

Son, Choi, Park, Bae and Lee In 2009 stated that when patients with ESRD start to receive HD, they may face a lot of chronic stress-related to restrictions on their time, the economic and vocational costs related to treatment, functional limitations, dietary constraints, and possible adverse effects of medications. AbdelKader, Unruh and Weisbord, (2009) stated that ESRD on maintenance dialysis and those with advanced CKD experience a similar overall burden of physical and emotional symptoms and depression and comparably low QOL. Patients with ESRD who are undergoing HD may experience stress, time restriction, dietary constraints, functional limitation, sexual dysfunction, medication effects, awareness of impending death and difficulties related to employment, social and family dynamics (Cukor, Scott, Peterson and Kimmel., 2007). In general, patients with HD have significantly reduced self-assessed physical and mental health compared to the general population (Kittal et al., 2001).

Patients with renal failure face many challenges due to their condition, which may leave them feeling fatigued and depressed. On the other hand, haemodialysis can threaten their body image, finances, relationships and independence. Nurses are always concerned about the physical, mental, psychological and social well-being of their patients. Therefore, it is of relevance to assess and understand the QOL among patients with CKD and who are undergoing haemodialysis in two teaching hospitals in Sri Lanka. 
The Nephrology, Dialysis and Transplant Unit of the National Hospital of Sri Lanka provides care for renal patients in the region. It consists of a dialysis unit with a dedicated healthcare team, and this is the first renal unit that has been established under the Ministry of Health and Nutrition. The number of dialysis sessions carried out in 2003 was little over 3000, and the numbers have dramatically increased to more than 11600 in 2013, and more than 6900 up to July 2014 (the average number of HD sessions per month are around 1000). The number of HD provided by NHSL in 3013 was 11669. (Nephrology statistics from NHSL, 2015). Dialysis is provided to patients with acute kidney injury and chronic renal failure, and to patients who are awaiting transplants.

\section{Significance of the study}

There is limited data regarding QOL among patients with CKD undergoing HD within the Sri Lankan context. Finding of this study may help to understand the views of patient's with HD about their health, performance capacities, sense of welfare and the benefits of the treatment procedure. Understanding the factors that influence the wellbeing of these patients may allow nurses to focus on specific interventions to enhance the quality of life of their patients. Furthermore, findings from this study may be more beneficial for nurses to plan better nursing care as they could have a better perception of physical and mental health status, abilities and limitation of these patients.

\section{General objective}

To assess the QOL of patients with CKD undergoing HD in two selected teaching hospitals, Sri Lanka.

\section{Specific objectives}

This study was conducted to identify the level of the physical, psychological, social and environmental health of patients with CKD undergoing HD.

\section{Literature Review}

Global burden of CKD

The Kidney Disease Outcomes Quality Initiative (KDOQI) of the 
National Kidney Foundation (NKF) established a definition and classification of CKD in 2002. According to that, CKD is defined as either kidney damage or a decreased glomerular filtration rate (GFR) of less than $60 \mathrm{~mL} / \mathrm{min} / 1.73 \mathrm{~m}^{2}$ for at least three months (KDOQI, 2002). The numbers affected with CKD in low- and middle-income countries (LMICs) were 177.4 million men and 210.1 million women. Thus, CKD is a critical global-health challenge, especially in LMICs (Mils et al., 2010) Stanifer et al. (2016) stated that environmental toxins and urbanisation exposes a growing number of people to numerous infectious diseases and noncommunicable diseases (NCD). This is a significant but poorly understood and rapidly growing health burden in LMICs, leading to significant morbidity and mortality due to treated cardiovascular disease and kidney diseases.

Furthermore, they noted that nearly 500 million people are estimated to have CKD, with the majority (80\%) living in LMICs. Worldwide, cause of death due to CKD is now ranked as $19^{\text {th }}$, which represents an increase of $82 \%$ since 1990. Alebiosu and Ayodele (2005) stated that the prevalence of CKD is higher in developing countries than in developed countries.

A Presidential Task Force (2017) has been established for the prevention of CKD in Sri Lanka. It confirms, according to the available health statistics, that there are approximately 20,000 admissions/ re-admissions of patients with renal failure to government hospitals with nearly 2,000 annual deaths approximately in Sri Lanka. Approximately 70,000 patients with CKD has been identified in known high-risk areas of which majority are from the North Central Province (The official website of the Presidential Task Force of Sri Lanka). Community screening for CKD was started in 2008, and so far, 38,000 patients with CKD have been identified. Anuradhapura and Polonnaruwa Districts had about 1,500 patients who have been identified with CKD annually during the past four years (Ministry of Health, 2015).

Jayasekara et al. (2015) conducted a cross-sectional study to identify the epidemiology of CKD of uncertain aetiology in Sri Lanka by analyzing health statistics. Three cohort studies were conducted $(n=15,630,3996$, and 2809$)$ to analyze the demographic information, age-specific prevalence, aetiology, and stage of presentation. Their results showed that the male-female ratio was $2.4: 1$, the mean age of patients was $54.7 \pm$ eight years, 
$92 \%$ of the patients were farmers, and $93 \%$ consumed water from shallow-dug wells. The familial occurrence was common (36\%). The majority of patients were stage $4(40 \%)$ at the first presentation, while $31.8 \%$ were stage 3 , and $24.5 \%$ were at stage 5. Stage one and two presentations accounted for only $3.4 \%$. Therefore, CKD is a devastating disease in Sri Lanka.

\section{Management of CKD}

The kidneys are responsible for filtering waste products from the blood in the human body. Dialysis is the procedure that substitutes for many of the normal functions of kidneys. Dialysis can allow individuals to live productive and useful lives, even though their kidneys can no longer work adequately. There are two main types of dialysis, namely haemodialysis (HD) and peritoneal dialysis (PD). Haemodialysis uses a particular kind of filter to remove excess waste products and water from the blood (Shiel, 2017).

Globally, 2.6 million patients with ESRD received HD in 2010. This number is projected to almost double to 5.4 million by 2030 (Vijaindren, 2017). Statistics from 2010 showed that approximately 414,000 patients were receiving dialysis in the United States. An additional number of patients of over 179,000 had a functioning kidney transplant for ESRD (National Kidney Foundation, 2002).

Quality Of Life among patients with CKD

According to WHO (2017) definition, Quality of Life (QOL) of a person is an individual perception about his/her culture and the value system in which he/she lives, and about standards and concerns. Furthermore, WHO also adds other factors such as a person's physical health, psychological state, level of independence social relationship, personal beliefs and relationships of their environment (WHOQOL measuring QOL, Division of mental health and prevention of substance abuse, WHO, 1997).

John and Thomas (2013) explored the psychosocial experience of patients with ESRD and its impact on QOL $(n=118)$ using semistructured face-to-face interviews with the WHOQOL questionnaire. They found that there was a considerable psychological burden for those with renal issues and a considerable impact on QOL for those living with ESRD.

Another descriptive correlational study was conducted in Iran by Ahmadzadeh (2016) about the evaluation of individual QOL 
among 53 patients with HD using a structured interview method. The author identified that the majority of the subjects was unemployed or disabled, only five were engaged in jobs, and they were in the lower-income category. Tilaki, Heidari, and Tilaki. (2017), conducted a case-control study in Iran, with 154 patients on HD and 308 healthy participants using a standard short-form questionnaire. Their result indicated that poor QOL among patients with HD.

In Greece, a qualitative and quantitative study was conducted by Gerogianni, Gerogianni, and Panagiotou (2016), their sample also included 100 patients, all of whom were assessed by intervieweradministered questionnaire. Researchers concluded that specific variables, such as age, gender, frequency and duration of dialysis, education, marital, financial and professional status, social functioning and effects of the renal disease could affect QOL of patients either positively or negatively.

Theofilou (2011) studied QOL in patients undergoing HD or peritoneal dialysis treatment. They assessed 144 patients using several tools namely, WHOQOL- BREF, General Health Questionnaire (GHQ-28) of Goldberg, State-Trait Anxiety Inventory, centre for Epidemiologic Studies Depression Scale (CES-D), and Multidimensional Health Locus of Control (MHLC). The author identified that the patients in HD treatment, compared to patients with PD treatment, had a more compromised QOL in the domains of environment and social relationships.

Another cross-sectional study was conducted by Edalat-Nejad, and Qlich-Khani., (2013) about the quality of sleep and healthrelated quality of life (HRQOL) in patients with HD in Iran. Quality of sleep was measured using the Pittsburgh Sleep Quality Index (PSQI), and HRQOL was measured using the Medical Outcomes Study 36-item Short Form (SF-36) in 115 patients with haemodialysis. The study concluded that poor sleep is common in dialysis patients and is associated with lower HRQO. Seckinger et al. (2016) conducted a prospective, longitudinal, nationwide, nonrandomized study in Germany among 2507 patients to assess QOL and treatment parameters, adverse and intercurrent events, hospitalisations, morbidity and mortality in the age groups $\geq 75$ and $<75$ years. The study found that the social QOL in elderly patients was more stable than in the younger cohort. In 2015 Gerasimoula et al. studied the influence of socio-demographic and clinical characteristics on the QOL in 320 patients undergoing HD in a one- 
day dialysis centre by using Missoula- VITAS QOL Index (MVQOLI). Authors found that participants with higher education had a better quality of life, possibly because education allows a more profound understanding of the disease and compliance with the therapeutic regimen. Another alternative explanation was that higher education might reflect higher income and consequently ability to afford treatment.

A cross-sectional study conducted by Tannor et al. (2017) in South Africa involved both qualitative and quantitative methods using 106 patients. The study used the KDQOL SF 3.1 questionnaire, and 36 of them participated in the focus group interview. The researchers found that patients on $\mathrm{PD}$ were more symptomatic and experienced more treatment-related limitations than those on HD. There was no difference in the overall QOL between patients with HD and PD.

A quantitative study by Michel(2016) with a group of 286 Brazilian patients with CKD on being treated with haemodialysis used a demographic questionnaire, KDQOL SF-36 and analysis of the electronic medical record. Results indicated that people with CKD have considerable trouble in keeping or going back to their jobs on account of various physical, psychological, and legal obstacles. Females had lower QOL scores than males in practically all areas, particularly in the domains related to physical symptoms and emotional wellness.

Donciu et al. (2013) conducted a cross-sectional study on the impact of end-stage renal disease on quality of life using the Short Form Health Survey Questionnaire (SF-36) in Romania $(n=102)$. The study concluded that HD patients experienced a more significant burden from physical and psychological symptoms of the disease, perceiving a considerable impairment in their QOL, especially related to the physical component.

Bayoumi et al. (2013) in Saudi Arabia studied the predictors of quality of life in haemodialysis patients $(n=100)$ using the SF-36 and KDQOL-SF forms covering six domains of QOL, namely, physical, emotional, social, illness impact, medical and financial satisfaction, and overall general health. The study concluded that QOL reduced in all the health domains of HD patients.

A cross-sectional study among 223 patients was conducted by Braga et al. (2011) to identify factors associated with health-related 
quality of life in elderly patients on haemodialysis in South-Eastern Brazil ( $n=223)$. QOL was measured with the Kidney Disease Quality of Life Short Form (KDQOL-SF) and the Medical Outcomes Study 36-Item Short-Form Health Survey (MOS SF-36). The study concluded that health-related QOL was consistently associated with chronic diseases points to the importance of the morbidity profile in elderly patients who are undergoing haemodialysis.

Briefly stated, several studies have been conducted in other countries regarding QOL among patient with CKD who are undergoing HD. However, in Sri Lanka, this area is not adequately studied. Therefore, the present study plans to assess the QOL with the focus on levels of physical, psychological and social health and the level of the environmental health of patients with CKD undergoing HD in two teaching hospitals, Sri Lanka. The findings of this may be useful for nurses to improve QOL among patients with CKD undergoing HD. Also, findings from this study may be more beneficial to nurses as they could have a perception about patients physical and mental health status and also their abilities and limitation which could influence them to plan and deliver better nursing care.

\section{Methodology}

\section{Study Design}

This study is a quantitative descriptive, cross-sectional study and was conducted at a Teaching hospital (TH) in Anuradhapura and the National Hospital of Sri Lanka (NHSL) as they are the two major hospitals in Sri Lanka which provide care for a large number of patients with CKD who are undergoing HD. The target population was patients with CKD, undergoing HD, and admitted to Dialysis Units (DU) of NHSL and TH Anuradhapura. Two hundred fifty participants (150 from NHSL and 100 from TH Anuradhapura) were selected under the following inclusion and exclusion criteria.

\section{Inclusion criteria}

Individuals who were diagnosed with CKD; age above 18 years; who can understand, read and write Sinhala, Tamil or English; and patients who have undergone HD for more than 03 months.

The following participants were excluded from the study: individuals less than 18 years of age and who were unable to speak, write or understand Sinhala, Tamil or English; patients who have 
undergone HD for less than three (03) months; patients who were suffering from severe mental disorders.

\section{Data collection}

This study used two types of questionnaires as follows: Part a) demographic data; Part b) WHO-QOL BREF. Permission was obtained from WHO to use the WHO-QOL BREF (1997) tool. An agreement was signed and emailed to the WHO group. Permission was obtained from the WHO team after emailing the details of the proposal. According to the user agreement, the researcher is not permitted to translate the Questionnaire to any language. So English, Sinhala and Tamil language versions were requested and got down through email from WHO (WHOQOL-BREF Field Trial Version, 1996). There are 04 main domains of WHOQOL -BREF. They are physical, psychological, social and environmental health.

Each patient's QOL was assessed using interviewer-administered questionnaire after obtaining the ethical approval from the ethics review committee of KAATSU International University (KIU). The questionnaire aimed at gathering relevant information on patients QOL of physical, psychological, social and environmental health. Participants were approached in DU while on HD.

\section{Data Analysis}

Descriptive statistics were used, and the result was presented as the sample mean, mode, median. SPSS version 23 statistical software and MS Excel 2013 were used to analyze the data. The WHOQOLBREF produces four domain scores. Two items were examined separately. The mean score of items within each domain was used to calculate the domain score.

According to the WHOQOL-BREF questionnaire, another 24 questions represent the physical, psychological, social and environmental domains. Each item was related to the 5 points Likert scale. The responses were scaled in a positive direction. According to the WHOQOL-BREF user manual, the mean score of the item within each domain was used to calculate the row score. Row score was then transformed to a 4-20 scale and 0-100 scale using a transformation formula. A higher score reflects a better QOL.

\section{Ethical considerations}

Ethical approval was obtained from the ethics review committee of KIU (reference number - KIU/ERC/17/011) before the data 
collection. Further approval was obtained from the Deputy Director of NHSL and Director of TH Anuradhapura. Also, permission was obtained from the Consultant Nephrologists and the Nurse in charge of DU in NHSL and TH Anuradhapura.

Participation in this study was voluntary. Participants were fully informed of their rights to decline or withdraw from participation in the study as desired. The questionnaires were administered to the participants after obtaining the informed written consent.

Confidentiality and anonymity were maintained by using codes to identify each participant. All information was in a locked file cabinet.

\section{Findings and Discussions}

\section{Results}

A pilot study was conducted with the questionnaire using ten patients. They were not included in the main study. Statistical analyses was performed using SPSS 23 software and MS Excel 2013. The total number of participants (250) were included in this study. Participants respond rate $100 \%$

\section{Demographic characteristics of the participants}

The median age was 30-49 yrs. According to the findings, most of the participants belonged to age groups 30-49 (39.6\%) and 50-64 $(39.6 \%)$. Majority of them were male 184 (73.6\%). Female to male proportion was $1: 2.78$. Most of the participants $(79.6 \%)$ belonged to the Sinhala ethnic community (199 out of 250), and 185 of them $(74 \%)$ were Buddhist. Two hundred twenty-four participants (89.6\%) had achieved secondary education. All most all of them were married (83.6\%). Out of 250 participants, 105 were unemployed (42\%), and few were farmers 10 (4\%). Average monthly income of $58.8 \%$ participants (147) was less than Rs. 29,999/-.121 participants (48.4\%) had undergone three months to one-year duration of HD. Among the sample, 134 participants (54\%) were admitted three times per week for HD.

\section{1. $Q O L$ of the participants}

A simulation study was conducted using WHOQOL-BREF. It contains 26 questions. The first two questions evaluated the overall perception of QOL and satisfaction with their health. As 
shown in Table 1, 135 (54\%) participants rated their QOL as neither poor nor good. Findings indicated that none of the participants was very satisfied with their health. An only a small amount of participants were satisfied (15.6) with their health.

Table 1. Overall perception of $\mathrm{QOL}$ and satisfaction with their health $(n=250)$

\begin{tabular}{lll}
\hline Characteristics & Frequency & Percentage \\
\hline Overall perception of QOL & & \\
Very poor & 20 & 8.0 \\
Poor & 66 & 26.4 \\
Neither poor nor good & 135 & 54 \\
Good & 23 & 9.2 \\
Very good & 06 & 2.4
\end{tabular}

Health satisfaction

$\begin{array}{lcc}\text { Very dissatisfied } & 30 & 12 \\ \text { Dissatisfied } & 89 & 35.6 \\ \begin{array}{l}\text { Neither satisfy } \\ \text { dissatisfied }\end{array} & 92 & 36.8 \\ \quad \text { Satisfied } & 39 & 15.6 \\ \text { Very satisfied } & 00 & 00\end{array}$

According to the WHOQOL-BREF, other 24 questions represent physical, psychological, social and environmental domains. Each item is measured with 5-points Likert scale. The response was scaled in a positive direction. According to the WHOQOL BREF User Manual, the mean score of the item within each domain was used to calculate the row score. Row score was transformed to a 4- 
20 scale and $0-100$ scale using a transformation formula. The higher score reflects a better QOL.

There are no cut-off points above or below which QOL could be evaluated as "poor" or "good" thus it was decided to consider $\mathrm{QOL}<60$ as poor; QOL and QOL $>60$ as good QOL when compared to a Brazilian study. The Brazilian study stated that OQOL $\geq 60$ cut-off point was moderately sensitive for recognizing individuals with good/satisfactory QOL in Brazilian older adults. On the other hand, the sensitivity of the test with the OQOL $<60$ cut-off point was optimum, as was poor/unsatisfactory (Silva, Soares, Santos, and Silva (2014).

\section{QOL of the participants under the physical domain}

Findings indicated that the patient had more concern about their pain. That physical pain prevents them from engaging in what they needed to do. There are $33(13.2 \%)$ participants with an extreme amount of pain and 93 out of 250 participants (37.2\%) who suffered from very much pain. It was difficult for $190(76 \%)$ participants to balance daily life without medical treatment, and 76 felt that they needed the extreme amount of medical treatment, and 114 felt the intense need for medical treatment.

Findings revealed that 101 participants (40.4\%) were neither satisfied nor dissatisfied with their ability to perform daily living activities. Most of the participants, 102 (40.8\%), were dissatisfied about their capacity for work. They cannot balance daily life. 21 $(8.4 \%)$ participants felt very satisfied with their sleep satisfaction.

0-100 scale of the physical domain was used to calculate the overall physical QOL. QOL $<60$ was considered as poor QOL, and QOL $>60$ as good QOL, as shown in Figure 1. All most all of the participants numbering 205 (82\%) experienced poor QOL, and 45 $(18 \%)$ participants experienced good QOL under the physical domain. 


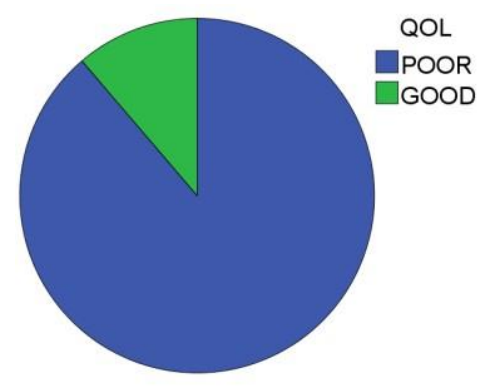

Figure 1. QOL of the participants under the physical domain

$$
(n=250)
$$

\section{QOL of the participants under the psychological domain}

There are 06 questions included under the psychological domain (Q5, Q6, Q7, Q11, Q12, Q19, Q26). Data revealed that 2.3, or 116 $(46.4 \%)$ of the participants were able to concentrate on things very much amount that in their daily living. Most of them, e 109 (43.6\%) of the total sample, accepted their bodily appearance as a moderate amount. However, 76 participants (30.4\%) enjoyed their life much, and $83(33.2 \%)$ fell under a moderate amount.

0-100 scale of the psychological domain was used to calculate the overall psychological QOL. QOL $<60$ was considered as poor QOL, and QOL $>60$ as good QOL. Figure 2 indicated that the majority of participants, numbering $160 \quad(64.8 \%)$ represented the poor QOL category, and 90 (35.2\%) of them represented the good QOL category under a psychological domain.

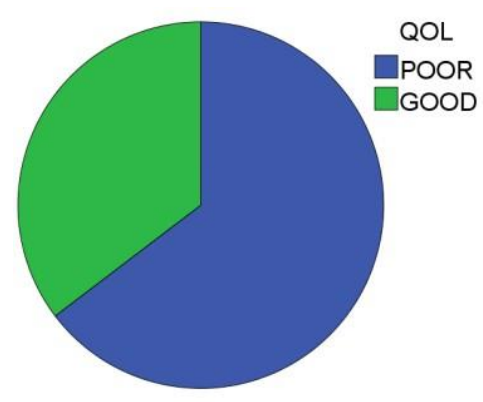

Figure 2. QOL of participants under the psychological domain $(n=250)$ 


\section{QOL of participants under the social domain}

There were 03 questions included in the social domain (Q20, Q21, Q22). Findings indicated that 95 individuals out of $250(38 \%)$ were satisfied with their relationships. Some indicated that they were undecided the support they received from their friends. Only a small number of participants was very satisfied $(4.4 \%)$ with their sex life.

0-100 scale of the social domain was used to calculate the overall social QOL. QOL $<60$ was considered as poor QOL, and QOL $>60$ as good QOL. As shown in Figure 3, 173 (69.2\%) participants out of 250 were viewed as those experiencing poor QOL, and 77 (35.2\%) of them were represented under the good QOL in the social domain.

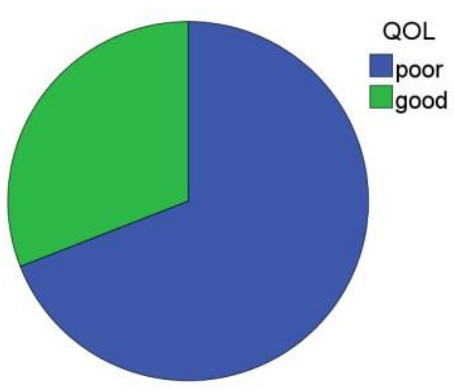

Figure 3. QOL of the participants under the social domain $(n=250)$

\section{QOL of the participants under the environmental domain} 08 questions represented the environmental domain $(Q 8, Q 9, Q 12$, Q13, Q14, Q23, Q24 and Q25). Data indicated that 109 (43.6\%) participants were satisfied with the conditions of their homes. More than $50 \%$ of the participants, 130 out of 250 , cited their physical environment category as 'healthy'. However, 92 (36.8\%) participants stated they had less money to meet their needs. There are 116 (46.4\%) participants out of 250 who were satisfied, and 67 (26.8\%) very satisfied with access to health services.

0-100 scale of the Environmental domain was used to calculate the overall Environmental QOL. QOL $<60$ was considered as poor QOL, 
and QOL $>60$ as good QOL. As shown in Figure 4, 132 participants (52.8\%) experienced poor QOL and 118 (47.2\%) participant experienced good QOL under the environmental domain.

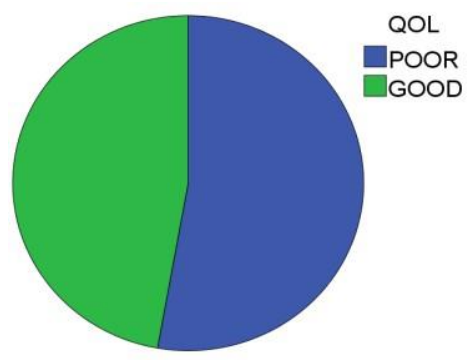

Figure 4. QOL of the participants under the environmental domain $(n=250)$

Above result indicated that participants experienced better QOL of the environmental domain than other domains.

\section{Overall $Q O L$ of the participants}

Overall QOL was calculated by the mean value of the above 04 domains. It included 24 questions. 0-100 scale of the overall QOL was used to calculate the overall QOL. QOL $<60$ was considered as poor QOL, and QOL $>60$ as good QOL. As shown in Figure 5, the majority of the participants 173 out of $250(69.2 \%)$ represented poor QOL, and $77(30.8 \%)$ of them good QOL. Therefore, the majority of patients with CKD having HD in two teaching hospitals, Sri Lanka experienced with poor QOL.

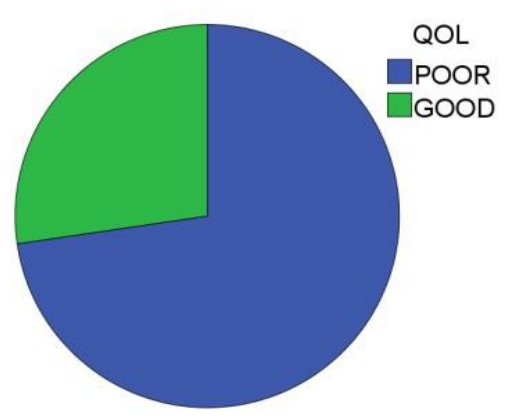

Figure 5. Overall QOL of the participants $(n=250)$ 


\section{Comparison of overall QOL with demographic data}

Two or more independent sample non-parametric test was performed to assess the difference between overall QOL and demographic data. As shown in Table 2, an education level $(p=0.000)$, average monthly income $(p=0.002)$ and the Frequency of dialysis $(p=0.000)$ and QOL were statistically significant. Therefore there is a difference between education level, average monthly income and the frequency of dialysis and QOL. Gender, ethnicity, religion, marital status, occupation and HD duration vs QOL was not statistically significant ( $p>0.05)$.

Table 2. Comparison of overall QOL with demographic data $(n=250)$

Compare group Significance level ( $p$ value)

QOL vs Gender $\quad 0.624$

QOL vs Ethnicity

0.566

QOL vs Religion

0.939

QOL vs Education level

$0.000^{*}$

QOL vs Marital status

0.747

QOL vs Occupation

0.346

QOL vs Average monthly income $\quad 0.002 *$

QOL vs HD Duration

0.246

QOL vs Frequency of Dialysis

$0.000^{*}$

*significant level $<0.05$ 


\section{Discussion}

Majority of the participants of this study were Sinhala $(79.6 \%)$, Buddhist (74\%), Male (73.6\%), married (83.6), under 18-64 age group (90.4\%), secondary level educated (89.6\%) and under 3month-1yr HD (48.4\%). Most of the participants were unemployed (42.2\%) and came under the lower-income category $(58.8 \%$ under <29999Rs). A similar study was done by Ahmadzadeh (2016), and they stated that all the participants had been treated for one year, and (86.8\%) were married. In terms of educational status, the majority of the participants were illiterate $(71.7 \%)$, and none had an academic degree. The majority was unemployed or disabled, and only five had jobs. All the patients indicated that they were in the lower-income category. Almost one-half earned 160 US dollars per month(Ahmadzadeh, 2016). Another study conducted in Malaysia revealed that the majority of the respondents were unemployed (Baizura et al., 2013). Another study was conducted in Chile, and they found that most participants were male $(57.9 \%)$, married $(53.7 \%)$, with a partner (68.6\%). On average, patients had 7.84 years of education; the majority declared being religious $(91 \%)$, professionally inactive $(77.1 \%)$ and with monthly economic revenues less than 5,000 Chilean Pesos (53.1\%), equivalent to less than 200 Dollars per month (Guerrero et al., 2012). Another study carried out in Greece stated that majority of the participants (69\%) were between 50-59 years old, and 44\% have been receiving HD for 01-03 year (Gerogianni et al., 2016). Contrasting findings were identified in terms of education (Ahmadzadeh, 2016; Guerrero et al., 2012) employment (Ahmadzadeh, 2016; Baizura et al., 2013; Guerrero et al., 2012).

In this study majority of the participants were reportedly experiencing poor physical (82\%), psychological (64.8\%), social $(69.2 \%)$ and environmental QOL (52.8\%). QOL under physical domain was lower than the other domain and QOL under environmental domain was higher than the other domains. Similarly, a study done in Nepal revealed that patients with CKD undergoing dialysis had overall low QOL scores in all four domains (Joshi et al., 2017).

The first two questions in this study evaluated that individuals' overall perception of QOL and satisfaction with their health. Around 54\% of participants rated their QOL to be in neither poor nor good category, and $34.4 \%$ (cumulative) participants were under 
the very poor and poor category. Around $15.6 \%$ of participants were satisfied with their health. In contrast, the Brazilian study stated that around $56.3 \%$ of the older adults perceived their quality of life to be good or very good, and $7.9 \%$ as poor or very poor; $52.4 \%$ were satisfied or very satisfied with their health, whereas $23.0 \%$ considered it to be dissatisfactory or very dissatisfactory (Silva et al., 2014).

In this study, $69.2 \%$ of participants were observed to be experiencing poor QOL, and 30.8\% participant good QOL. Therefore the majority of the participants were experiencing poor QOL. Similarly, an Indian study found that the overall QOL of patients on HD was significantly impaired (Abraham et al., 2012).

In this study, the education level $(p=0.000)$, average monthly income $(p=0.002)$ and the frequency of dialysis $(p=0.000)$ and $Q O L$ were statistically significant. Therefore, there is a connection between the education level and average monthly income in QOL. However, gender, ethnicity, religion, marital status, occupation and HD duration are not statistically significant towards QOL. Similar studied conducted previously stated that the relationships between the QOL scores and education, job and marital status were not statistically significant (Ahmadzadeh, 2016). Another study found that participants of higher education had a better quality of life, possibly because education allows an in-depth understanding of the disease and compliance with the therapeutic regimen. Another alternative explanation is that higher education may reflect higher income and consequently, the ability to afford treatment (Gerasimoula et al., 2015). A similar study conducted in Iran revealed that older age, female gender, and lower educational level were significantly associated with a lower score of all physical, psychological, and social domains of QOL (Tilaki et al., 2017).

Findings of this study provide healthcare providers with ways to identify the patients' quality of life as well as to plan and implement strategies to help enhance it. It can also educate the patients by increasing their awareness of conditions that may affect their quality of life.

\section{Conclusions}

The findings revealed that majority of participants were from the Sinhala ethnic community, Buddhist, male, married, under 18- 
64 age group were exposed to secondary level education, were undergoing HD for three months to 1year duration and participated in HD three times a week. Majority of the participants experienced poor QOL under each domain. However, QOL of the environmental domain was better than other domains and QOL of the physical domain lower than the other domain when compared to each other. Therefore, the majority of the patients with CKD undergoing HD in two teaching hospitals in Sri Lanka experienced poor QOL.

The education level $(p=0.000)$, average monthly income $(p=0.002)$ and the frequency of dialysis towards QOL are statistically significant. Therefore there is a difference between the education level, average monthly income and the frequency of dialysis and QOL.

Understanding of QOL in haemodialysis patients is useful for nurses when developing individualized interventions based on their personal needs and delivering holistic care to this population.

\section{Limitations}

This study was conducted only in two teaching hospitals. Therefore, the results cannot be generalized to the whole country.

\section{Recommendations}

There should be an awareness programme to improve the QOL of patients with CKD undergoing HD in Sri Lanka. There should be an educational programme to improve the nurses' further knowledge about a person's perception of QOL. Further study with a larger sample is recommended.

\section{Acknowledgements}

We want to thank all participants and staff of the Dialysis Unit 1,2 of the National Hospital of Sri Lanka and Teaching Hospital Anuradhapura.

\section{References}

Abdel-Kader, K., Unruh, M. L., \& Weisbord, S. D. (2009). Symptom Burden, Depression, and Quality of Life in Chronic and End- 
Stage Kidney Disease.Clinical Journal of the American Society of Nephrology 4(6), 1057-1064 http://doi.org/10.2215/CJN.00430109.

Abraham, S., Venu, A., Ramachandran, A., Chandran, P.M, Raman, S. (2012) Assessment of quality of life in patients on hemodialysis and the impact of counselling. Saudi Journal of Kidney Disease Transplant, 23(5):953-7.

http://doi.org/10.4103/1319-2442.100875.

Ahmadzadeh, H.M.S. (2016). Evaluation of individual quality of lifeamong hemodialysis patients, Journal of Patient Preference and Adherence, 1-9.

https:/dx/doi.org/ 10.2147/PPA.S1 17860

Alebiosu, C.O. \& Ayodele, O.E. (2005). Journal of Advance Chronic Kidney Disease,5-13.

http://doi.org/10.1053/j.ackd.2010.02.001

Anu, V. K., Pushpa, P., \& Kumar, S. S. (2014). Quality of Life of Patients undergoing Haemodialysis at BP Koirala Institute of Health Sciences. Journal of Manmohan MemorialInstitute of Health Sciences, 1(2), 19-2

DOI: https://doi.org/10.3216/jmmihs.v1i2.9904

Bayoumi, M., Al Harbi, A., Al Suwaida, A., Al Ghonaim, M., Al

Wakeel, J., \& Mishkiry, A. (2013). Predictors of quality of life in hemodialysis patients. Saudi Journal of Kidney Disease Transplant, 24(2):254-9.

http://doi.org/10.5144/0256-4947.2012.570.

Baizura, N., Yusop, Mun, C.Y., Shariff, Z.M., \& Huat, C.B. (2013). Factors Associated with Quality of Life among Hemodialysis Patients in Malaysia, Volume 8 | Issue 12. http://doi.org/10.1371/journal.pone.0084152.

Braga, S.F., Peixoto, S.V., Gomes, I.C., Acúrcio, Fde, A., Andrade, E.I., \& Cherchiglia, M.L. (2011). Rev Saude Publica, 45(6): 1127-36

https://doi.org/10.1590/s0034-89102011000600015

Cukor, D., Scott, D.C., Peterson, R.A., \& Kimmel, P.L. (2007). Psychosocial Aspects of Chronic Disease: ESRD as a Paradigmatic Illness, Journal of the American society nephrology.https://doi.org/10.1681/ASN.2007030345

Donciu, M.D., Tasmoc, A., Dumea, R., Hogas, S., Voroneanu, L., Siriopol, M.D. \& Covic, A. (2013). The impact of end-stage 
renal disease on quality of life. Rev Med Chir Soc Med Nat Iasi, 117(4):908-15.

Edalat-Nejad, M., \& Qlich-Khani, M. (2013). Quality of life and sleep in Hemodialysis patients. Saudi Journal of Kidney Diseases and Transplantation, 24(3), 514. https://doi.org/10.4103/1319-2442.111031

Finnegan-john, J., \& Thomas, V. J. (2013). The Psychosocial Experience of Patients with End-Stage Renal Disease and Its Impact on Quality of Life, Journal of ISRN Nephrology, 3-6. https://doi.org/ 10.5402/2013/308986.

Gerasimoula, K., Lefkothea, L., Maria, L., Victoria, A., Paraskev i, T. \& Maria, P. (2015). Quality of life of haemodialysis patients, Journal of Mater Sociomed; 27(5): 305-309. https://doi.org/ 10.2147/IJNRD.S136522

Gerogianni, S., Gerogianni, G., \& Panagiotou, M. (2016). Social Life of Patients Undergoing Haemodialysis, Journal of Caring Sciences, Volume 9, Issue 1, Page123.

Grove, S.K., Grey, J.R. \& Burns, N.(2015). Understanding Nursing Research, Building and evidence-based practise $6^{\text {th }}$ edition, p 33, 212-213.

Guerrero, V.G., Alvarado, O.S., Espina, M.C. (2012). Quality of life in people with chronic hemodialysis: association with sociodemographic, medical-clinical and laboratory variables, 20(5):838-46

https://doi.org/10.1590/s0104-11692012000500004

Heidari, B. (2017). A Comparison of Health-related Quality of Life in Patients with Renal Failure under Hemodialysis and HealthyParticipants, Saudi Journal of Kidney Disease Transplant; 28(1),133-140. https://doi.org/10.4103/13192442.198165

Ivey, T., \& Lane, B. (2011). Quality of Life in Patients with End-Stage Renal Disease on Hemodialysis.

Jayasekara, K. B., Dissanayake, D. M., Sivakanesan, R., Ranasinghe, A.,

Karunarathna, R.H., \& Priyantha Kumara, G. W. G. (2015). Epidemiology of Chronic Kidney Disease, With Special Emphasis on Chronic Kidney Disease of Uncertain Etiology, in the North Central Region of Sri Lanka. Journal of Epidemiology, 
25(4), 275-280. https://doi.org/10.1007/s13201-0180792-9

John, J.F. \& Thomas, V.J. (2013). The Psychosocial Experience of Patients with End-Stage Renal Disease and Its Impact on Quality of Life: Findings from a Needs Assessment to Shape a Service," ISRN Nephrology, Article ID308986, 8 pages, https://doi.org/10.5402/2013/308986.

Joshi, U., Subedi, R., Poudel, P., Ghimire, P.R., Panta, S., \& Sigdel, M.R. (2017). Assessment of quality of life in patients undergoing hemodialysis using WHOQOL-BREF questionnaire: a multicenter study. International Journal of Nephrology and Renovascular Disease, Pages 195-203 https://doi.org/10.2147/IJNRD.S136522.

Jha, V., Garcia-Garcia, G., Iseki, K., Li, Z., Naicker, S,. Plattner, B,. Saran, R,. Wang, A.Y, \& Yang, C.W. (2013). The effect of spirituality on quality of status of life patients with chronic kidney disease and its correlation with the mental health status and cognitive perception for their illness, Open access library journal, $(2,8)$.

https://doi.org/ 10.1016/S0140-6736(13)60687-X.

Levey, A.S., Jong, P.E.D., Coresh, J., Nahas, M.E.I., Astor, C.B., Matsushita, K., Gansevoort, R.T., Kasiske, B.L., \& Eckardt, K.U. (2011). Kidney International, Volume80, Issue 1, 2011, pp. 17-28 https://doi.org/10.4236/ijcm.2016.77053

Long, M., Wilkinson., Baldwin, A., \& Wallin, E. ( 2014). Chronic kidney disease. Oxfordhandofclinicalmedicine.

https://doi.org/10.1093/med/9780199204854.003.2106

Michel, R. B. (2016). Quality of life in hemodialysis patients and the relationship with mortality, hospitalization and poor treatment adherence, JournalofBrasNefrol;38(4):411-420411-420.

https://doi.org/10.5935/0101-2800.20160066.

Mills, K.T., Xu, Y., Zhang, W., Bundy, J.D., Chen, C.-S., Kelly, T.N., Chen, J., \& He, J.A (2015). Systematic analysis of worldwide population-based data on the global burden of chronic kidney disease.

Journal of kidneyinternational,88(5):950-7. https://doi.org/ 10.1038/ki.2015.230.

National Hospital of Sri Lanka (2015). Retrieved from http://www.nhsl.health.gov.lk/web (Government of Sri Lanka Web Portal Retrieved Jan 18, 2018, Ministry of Health 
Web Portal National Kidney Foundation (NKF). (2002). The Kidney Disease Outcomes Quality Initiative (KDOQI) Retrieved from https://www.kidney.org/atoz/content/about-chronickiney- disease\#ckd

Ojo, A. (2014). Addressing the Global Burden of Chronic Kidney Disease Through Clinical and Translational Research. Transactions of the American Clinical and Climatological Association, 125, 229-29. Press, D. (2017). Evaluation of individual quality of life among hemodialysis patients, Patient Preference and Adherence: 11, Presidential Task Force of Sri Lanka (Official website) Retrieved from, https://www.presidentialtaskforce.gov.lk/en/kidney.html\# doi.org/10.1186/s12955-017-0697-6

Ranasinghe, P., Perera, Y. S., Makarim, M. F. M., Wij single, A., \&Wanigasuriya, K. (2011). The costs in the provision of haemodialysis in a developing country : JournalofBMCNephrology, 12:42 https:/ / doi.org/ 10.1186/1471-2369-12-42

Seckinger, J., Dschietzig, W., Leimenstoll, G., Rob, P. M., Kuhlmann, M. K., Pommer, W., Fraass, U., Ritz, E. \& Schwenger, V. (2016). Morbidity, mortality and quality of life in the ageing haemodialysis population: ClinicalKidneyJournal,vol.9,(6),839-84 https://doi.org/10.1093/ckj/sfw087

Shiel, (eds.). (2017). The medical information website, MedicineNet.com. Retrieved On Jan15,2018. Retrieved from https://www.medicinenet.com/dialysis/article.htm

Silva, P. A. B., Soares, S. M., Santos, J. F. G., \& Silva, L. B. (2014). Cut-Off point for WHOQOL-bref as a measure of the quality of life of older adults. RevistadeSaúdePública,48(3),390-397. Retrieved from http://doi.org/10.1590/S0034-8910.2014048004912

Son, Y.J., Choi, K.S., Park, Y.R., Bae, J.S., \& Lee J.B., (2009).Depression, symptoms and the quality of life in patients on hemodialysis for end-stage renal disease. $A m j$ Nephrol ,29,36-42.

Sunil. (2014). Chronic kidney disease spreads in rural Sri Lanka. Published by the International Committee of the Fourth 
International (ICFI). Worldsocialistwebsite. Retrieved from https://www.wsws.org/en/articles/2014/03/05/slfmm05.html.

Stanifer, J. W., Muiru, A., Jafar, T. H., \& Patel, U. D. (2016). Chronic kidney disease in low- and middle-income countries. Nephrology Dialysis Transplantation, 31(6), 868-874. doi: $10.1093 / \mathrm{ndt} / \mathrm{gfv} 466$.

Tannor, E. K., Archer, E., Kapembwa, K., Schalkwyk, S. C. Van, \& Davids, M. R. (2017). Quality of life in patients on chronic dialysis in South Africa: BMC Nephrology, doi: 10.1186/s 12882-016-0425-1.

Theofilou, P (2011). Quality of Life in Patients Undergoing Hemodialysis or Peritoneal Dialysis Treatment. Journal of Clinical Medicine Research, 3(3), 132138. doi: $10.4021 /$ jocmr552w.

The Presidential Task Force of Sri Lanka (Official website) Retrieved from

http://www.presidentialtaskforce.gov.lk/en/kidney.html\#

Tilaki, K.H, B., Heidari.B., Tilaki, A.H. (2017). A Comparison of Health-related Quality of Life in Patients with Renal Failure under Hemodialysis and Healthy Participants. Saudi J Kidney Dis Transpl 2017;28(1):133-140

Vijaindren, A. (2017). 22nd report of the Malaysian Dialysis and transplant Registry.

Wang, L., \& Chen, C. (2009). The Psychological Impact of Hemodialysis on Patients with Chronic Renal Failure. ( www.intechopen.com).

The WHOQOL Group. (1998). Development of the WHOQOL-BREF Quality of Life Assessment. Psychological Medicine.(WHOQOL measuring QOL, Division of mental health and prevention of Substance abuse, WHO, 1997). Retrieved from http://www.who.int/healthinfo/survey/whoqolqualityoflife/en/

World health organization (2014). Non-communicable disease (NCD) country profiles, SriLanka. 